\title{
Association of the rs2071559 (T/C) polymorphism with lymphatic metastasis in patients with nasopharyngeal carcinoma
}

\author{
$\mathrm{KAI} \mathrm{HU}^{1 *}$, XIUJING XIE ${ }^{2 *}$, RENSHENG WANG $^{1}$, FANG WU $^{1}$ and YONG ZHANG ${ }^{1}$ \\ ${ }^{1}$ Department of Radiation Oncology, The First Affiliated Hospital of Guangxi Medical University, \\ Nanning, Guangxi 530021; ${ }^{2}$ Department of Ultrasonic Medicine, The First Affiliated Hospital, \\ School of Medicine, Zhejiang University, Hangzhou, Zhejiang 310003, P.R. China
}

Received August 21, 2015; Accepted January 12, 2017

DOI: $10.3892 / 01.2017 .7209$

\begin{abstract}
Vascular endothelial growth factor $(V E G F)$ and its receptor, VEGFR2, serve a critical role in angiogenesis and lymphangiogenesis, which are involved in the initiation and progression of malignancies. Specific single nucleotide polymorphisms of $V E G F$ and $V E G F R 2$ have been shown to modulate gene expression and influence malignancy aggressiveness. The aim of the present study was to determine whether the VEGFR2 rs2071559 (T/C) polymorphism is associated with the risk of developing nasopharyngeal carcinoma (NPC) and the aggressiveness of NPC in a southern Chinese population. A case-control study comprising 171 NPC patients and 184 healthy individuals was performed. Genotyping of the rs2071559 polymorphism was performed by quantitative polymerase chain reaction using TaqMan probes. Genotype and allele distribution of the rs2071559 polymorphism was not associated with the risk of NPC following adjustment for age, sex and ethnicity by multivariate logistic regression analyses. Regional lymph node metastasis was significantly correlated with the rs2071559 $\mathrm{C}$ allele and the related genotypes (OR $0.402,95 \%$ CI $0.193-0.835, \mathrm{P}=0.016$; and OR $0.347,95 \%$ CI $0.145-0.829, \mathrm{P}=0.024$, respectively). No correlations between genotype or allele distribution and the primary tumor size, distant metastasis, clinical stage, or histological type were observed. The rs2071559 polymorphism was shown to have an association with lymphatic metastasis in patients with NPC; however, the precise molecular mechanism should be elucidated in additional studies.
\end{abstract}

Correspondence to: Professor Yong Zhang, Department of Radiation Oncology, The First Affiliated Hospital of Guangxi Medical University, 6 Shuangyong Road, Nanning, Guangxi 530021, P.R. China

E-mail: zhangyonggxmu@163.com

${ }^{*}$ Contributed equally

Key words: rs2071559, nasopharyngeal carcinoma, single nucleotide polymorphism, vascular endothelial growth factor receptor-2

\section{Introduction}

Nasopharyngeal carcinoma (NPC) is commonly observed in southern China, particularly in the Pearl River delta area and the Xijiang River basin in the Guangdong and Guangxi provinces, with an incidence rate as high as $25-50$ per 100,000 between 2000 and $2002(1,2)$. The etiology of NPC is considered a result of unique interactions among environmental and genetic factors, but a detailed mechanism is yet to be elucidated. Studies have shown that gene polymorphisms not only influence gene expression or the function of the encoded protein, but may also affect individual susceptibility to NPC or the severity of the disease (3).

In a New England Journal of Medicine article published in 1971, Judah Folkman first proposed the hypothesis that angiogenesis was essential to cancer cell growth, and that angiogenesis inhibition could be a target for cancer therapy (4). A substantial body of preclinical and clinical evidence shows that vascular endothelial growth factor $(V E G F)$ and its receptors serve a crucial role in tumor-related angiogenesis $(5,6)$. Vascular endothelial growth factor receptor-2 (VEGFR2, also known as kinase insert domain-containing receptor) is considered to be the most important type of receptor for angiogenesis during tumor invasion (7). Numerous studies have shown that VEGFR2, not VEGF or VEGFR1, is associated with tumor prognosis and response to therapy $(8,9)$. Specific single nucleotide polymorphisms (SNPs) of VEGFR2 that modulate angiogenesis have been associated with an increased risk of malignancy and higher cancer aggression (10-12). The rs2071559 polymorphism is located in the promoter region of VEGFR2 and certain studies have found that this polymorphism affects mRNA and protein expression (13). However, little is known about the association between rs2071559 and the etiology, prognosis and tumor-node-metastasis (TNM) stage of NPC. The aim of the present study was to determine whether the rs2071559 polymorphism in the VEGFR2 gene is associated with the risk of developing NPC and associated cancer invasiveness.

\section{Materials and methods}

Study subjects. A total of 171 incident NPC cases were consecutively recruited from the First Affiliated Hospital 


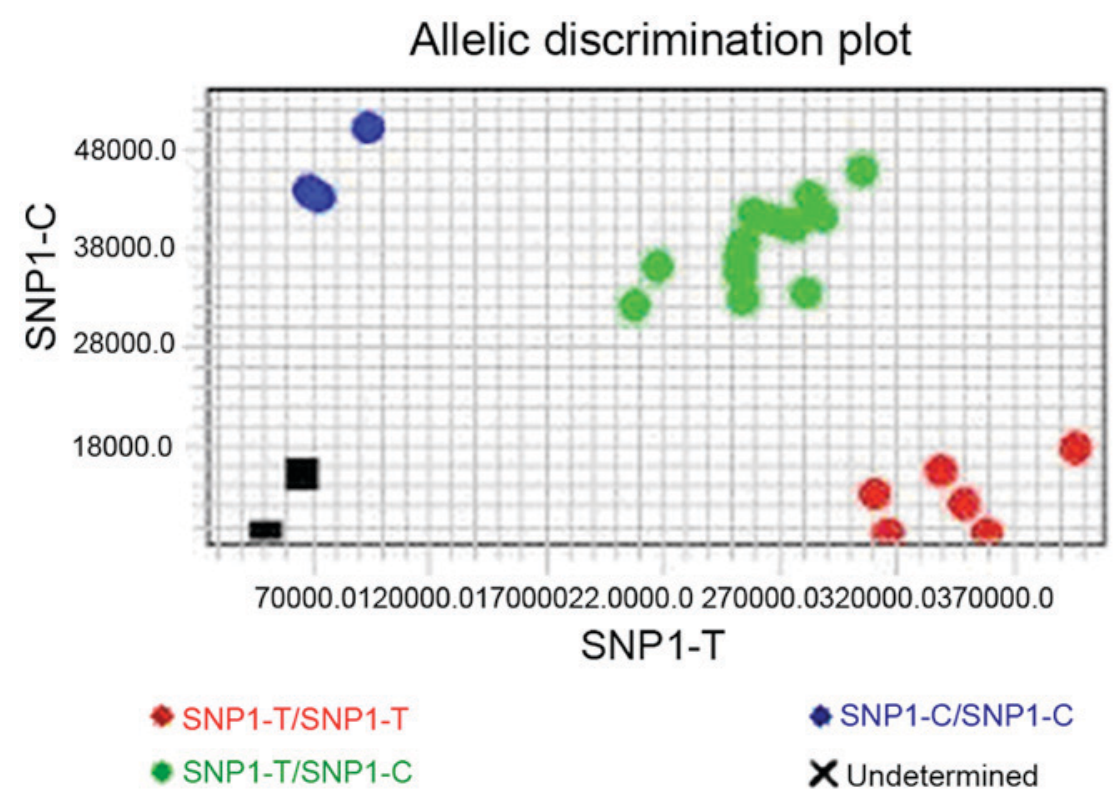

Figure 1. Allelic discrimination using TaqMan quantitative polymerase chain reaction. The blue points represent CC homozygous individuals. The green points represent TC heterozygous individuals. The red points represent TT homozygous individuals. The black points represent undetermined individuals. SNP, single nucleotide polymorphism.

of Guangxi Medical University of Nanning City (Nanning, China) between June 2009 and June 2010. All subjects were genetically unrelated and were from Nanning and the surrounding regions in China. The inclusion criteria were as follows: i) Newly diagnosed NPC; ii) no previous history of malignant tumors of other organs; iii) pathologically diagnosed as NPC. The histological type was confirmed by 2 independent pathologists according to the World Health Organization classification (14). TNM stage designation was performed according to the definitions of the 2009 edition of Union for International Cancer Control-American Joint Committee on Cancer clinical staging criteria (15). There was no ambiguity in the diagnosis. The control group was comprised of 184 unrelated healthy peripheral blood donors who visited the general health check-up division at the same hospital. Selection criteria for the control group included having no evidence of any personal or family history of cancer or other serious illness. The control group was comparable to the NPC cases with respect to age, sex and ethnicity. General information about the healthy controls was extracted from a standard questionnaire. Written informed consent was obtained from all subjects. All participants agreed to participate in the study and provided peripheral blood samples. The present study was approved by the Ethics Committee of Guangxi Medical University.

Genotype analysis. Genomic DNA was extracted from peripheral blood using a commercially available kit, according to the manufacturer's protocol (AxyPrep Blood Genomic DNA Miniprep kit; Axygen; Corning Incorporated, Corning, NY, USA). The rs2071559 polymorphism was detected using TaqMan probe-based polymerase chain reaction (PCR) and the PCR primers were designed by us based on the GenBank reference sequence and primer 5.0 (16). This method was carried out by PCR amplification using the primers: rs2071339 forward, 5'-GCTCTTAATCAGAAAACGCACTTG-3' and reverse, 5'-GGCTAGGCAGGTCACTTCAAA-3'; the allele T TaqMan probe 5'-FAM-CAGTTCGCCAACATTCCC GCT-TAMRA-3'; and the allele C TaqMan probe 5'-HEX-AGT TCGCCAGCATTCCCGCT-TAMRA-3' in a $10 \mu \mathrm{l}$ reaction mixture containing $\sim 80 \mathrm{ng}$ genomic DNA, $0.45 \mu \mathrm{l}$ of each primer, and $0.25 \mu \mathrm{l}$ of each probe. Reactions were cycled with the following parameters: Preheat at $60^{\circ} \mathrm{C}$ for $1 \mathrm{~min}$ and then at $95^{\circ} \mathrm{C}$ for $10 \mathrm{~min}$, followed by 40 cycles of $95^{\circ} \mathrm{C}$ for $5 \mathrm{sec}$ and $60^{\circ} \mathrm{C}$ for $31 \mathrm{sec}$, and finally, a final post-read for $1 \mathrm{~min}$. Genotype analysis was automatically generated by Applied Biosystems ${ }^{\circledR} 7500$ Real-Time PCR system (Thermo Fisher Scientific, Inc., Waltham, MA, USA). We did not repeat the experiment, but validated it by direct sequencing.

Statistical analysis. The $\chi^{2}$ test and Student's t-test were used to compare differences in sex and age distribution between nasopharyngeal carcinoma patients and the healthy control group. The Hardy-Weinberg equilibrium was verified by the calculation of genotype frequencies. Univariate and multivariate logistic regression analyses were used to estimate the correlation between rs2071559 polymorphism and NPC risk by computing the odds ratio (OR) and $95 \%$ confidence interval (CI), while accounting for confounding factors such as sex and age. In all statistical tests, $\mathrm{P}<0.05$ was considered to indicate a statistically significant difference. All statistical analyses were performed with statistical analysis system software (SPSS 16.0; SPSS, Inc., Chicago, IL, USA).

\section{Results}

$q P C R$. qRT-PCR with TaqMan probes was used to identify the genotype of the rs2071559 polymorphism in patients with NPC and healthy controls (Fig. 1). The $\mathrm{C}$ and $\mathrm{T}$ alleles were each associated with a different fluorescent label. The fluorescence signal generated by homozygotes was small, while heterozygotes produce 2 different fluorescence signals. Although the 
A

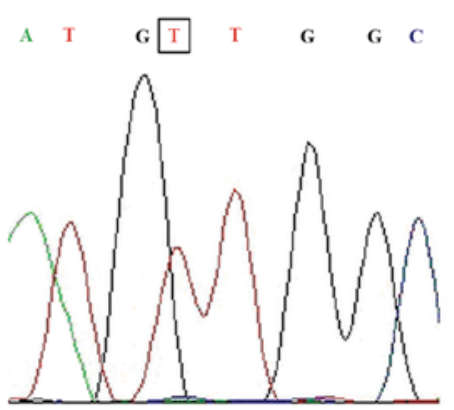

B

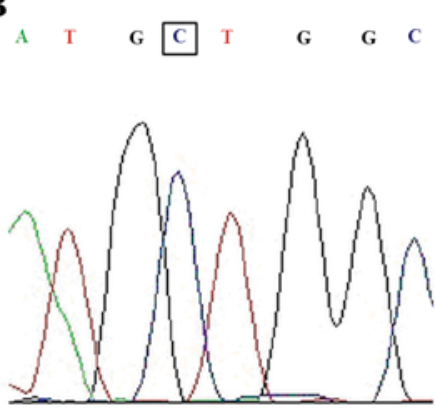

C

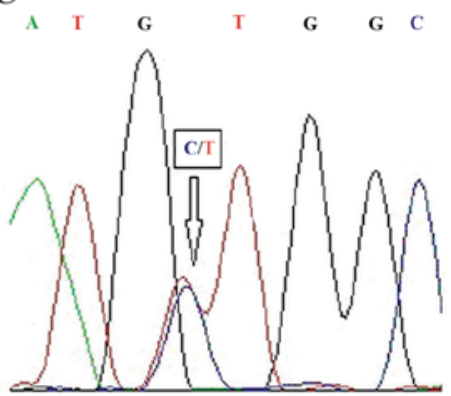

Figure 2. Sequences of 3 rs2071559 genotypes. (A) TT homozygote, (B) CC homozygote, and (C) TC heterozygote.

Table I. Clinical characteristics of patients with NPC and healthy controls.

\begin{tabular}{|c|c|c|c|}
\hline Characteristics & Patients & Controls & P-value \\
\hline Sex & & & 0.061 \\
\hline Male & 122 & 114 & \\
\hline Female & 49 & 70 & \\
\hline Age, mean $\pm S D$ & $44.17 \pm 11.34$ & $43.99 \pm 12.74$ & 0.845 \\
\hline \multicolumn{4}{|l|}{ Histological type } \\
\hline UCNT & 112 & - & - \\
\hline DNKC & 59 & - & \\
\hline \multicolumn{4}{|l|}{ Tumor size } \\
\hline $\mathrm{T} 1$ & 2 & - & - \\
\hline $\mathrm{T} 2$ & 40 & - & \\
\hline $\mathrm{T} 3$ & 65 & - & \\
\hline $\mathrm{T} 4$ & 64 & - & \\
\hline \multicolumn{4}{|l|}{ Lymph node status } \\
\hline N0 & 16 & - & - \\
\hline N1 & 41 & - & \\
\hline N2 & 89 & - & \\
\hline N3 & 25 & - & \\
\hline \multicolumn{4}{|l|}{ Distant metastasis } \\
\hline Yes & 18 & - & - \\
\hline No & 153 & - & \\
\hline
\end{tabular}

SD, standard deviation; UCNT, undifferentiated carcinoma of nasopharyngeal type; DNKC, differentiated non-keratinizing carcinomas; NPC, nasopharyngeal carcinoma.

amplification efficiency of each sample is not exactly the same, the genotypes cluster together.

Sequencing of rs2071559 genotypes. In order to verify the accuracy and reliability of the qPCR results, the present study sequenced each allele separately (Fig. 2). The 3 DNA sequences in Fig. 2 represent the TT, TC, and CC genotypes. The sequencing results validated the qPCR results.

rs2071559 polymorphism and NPC risk. The differences in age and sex between the 171 patients with NPC and 184 healthy controls were not statistically significant $(\mathrm{P}=0.061$ and $\mathrm{P}=0.845$, respectively; Table I). The genotype frequencies for the NPC cases and controls were in agreement with the Hardy-Weinberg equilibrium (0.055 for NPC and 0.388 for controls). The genotype or allele distribution of the rs2071559 polymorphism had no significant association with the risk of NPC following adjustment for age, sex and ethnicity by multivariate logistic regression analyses. The $\mathrm{P}$-values were as follows: Co-dominant model, 0.994 and 0.200; dominant model, 0.736; recessive model, 0.253 and allele model, 0.394 (Table II).

rs2071559 polymorphism and the aggressiveness of NPC. Clinical characteristics of patients with NPC including tumor size, lymph node metastasis, distant metastasis, clinical stage and histological type of cancer were analyzed. The distribution of genotypes and alleles of the rs2071559 polymorphism for NPC patients with tumor characteristics is shown in Table III. Earlier lymph node status according to the TNM staging system was significantly associated with rs2071559 C allele and the related genotypes (OR 0.402, 95\% CI 0.193-0.835, $\mathrm{P}=0.016$; and OR 0.347, 95\% CI 0.145-0.829, $\mathrm{P}=0.024$, respectively; Table III). However, no significant correlations were identified between the genotype or allele distribution and the primary tumor size, distant metastasis, clinical stage or histological type (Table III).

\section{Discussion}

To the best of our knowledge, this is the first study targeting the association between the rs2071559 polymorphism and patients with NPC in a cohort from south China. The present study found that patients with NPC with the rs2071559 C allele and the related genotypes appeared to have lower risk of N3 lymph node metastases according to the TNM staging system, implying that the rs2071559 C allele may decrease the migratory ability and suppress the aggressiveness of NPC cells.

Bioinformatic analysis suggested that the rs2071559 polymorphism is located in the binding site for transcriptional factor E2F (involved in cell cycle regulation and interacts with $\mathrm{Rb}$ p107). The transition from the $\mathrm{T}$ allele to the $\mathrm{C}$ allele leads to the disappearance of the binding site for transcriptional factor E2F, which suppresses transcriptional activity and reduces the expression of VEGFR2 (13). Consequently, An et al (17) found that the VEGFR2 polymorphism was only associated with mRNA expression and had no association with protein 
Table II. Comparison of NPC patients and controls by genotype frequencies of rs2071559 polymorphism.

\begin{tabular}{|c|c|c|c|c|c|}
\hline Variable & Genotype & Control & Patient & Adjusted OR $(95 \% \mathrm{CI})^{\mathrm{a}}$ & $\mathrm{P}$-value \\
\hline \multirow[t]{3}{*}{ Co-dominant model } & $\mathrm{TT}$ & 66 & 65 & 1 & \\
\hline & $\mathrm{CT}$ & 93 & 90 & $0.998(0.633-1.573$ & 0.994 \\
\hline & $\mathrm{CC}$ & 25 & 16 & $0.623(0.302-1.286)$ & 0.200 \\
\hline \multirow[t]{2}{*}{ Dominant model } & $\mathrm{TT}$ & 66 & 65 & 1 & \\
\hline & $\mathrm{CC}+\mathrm{CT}$ & 118 & 106 & $0.919(0.582-1.417)$ & 0.736 \\
\hline \multirow[t]{2}{*}{ Recessive model } & $\mathrm{TT}+\mathrm{CT}$ & 159 & 155 & 1 & \\
\hline & $\mathrm{CC}$ & 25 & 16 & $0.664(0.325-1.283)$ & 0.253 \\
\hline \multirow[t]{2}{*}{ Allele model } & $\mathrm{T}$ & 225 & 220 & 1 & \\
\hline & $\mathrm{C}$ & 143 & 122 & $0.873(0.643-1.183)$ & 0.394 \\
\hline
\end{tabular}

${ }^{a}$ Adjustment for age, sex and ethnicity. Logistic regression analysis was employed to assess the associations between genotypes and the risk of nasopharyngeal carcinoma. NPC, nasopharyngeal carcinoma; OR, odds ratio; CI, confidence interval.

Table III. Stratification analyses of the rs2071559 polymorphism with clinical characteristics of NPC patients.

\begin{tabular}{|c|c|c|c|c|}
\hline \multirow[b]{2}{*}{ Characteristics } & \multicolumn{2}{|c|}{ Dominant model } & \multicolumn{2}{|c|}{ Allele model } \\
\hline & OR $(95 \% \mathrm{CI})$ & P-value & OR $(95 \% \mathrm{CI})$ & P-value \\
\hline Age (years) & & & & 0.233 \\
\hline$\leq 40$ & 1 & & 1 & \\
\hline$>40$ & $1.240(0.648-2.370)$ & 0.618 & $1.365(0.848-2.198)$ & \\
\hline Sex & & & & 0.456 \\
\hline Male & 1 & & 1 & \\
\hline Female & $0.752(0.383-1.478)$ & 0.486 & $0.801(0.488-1.314)$ & \\
\hline Nation & & & & 0.708 \\
\hline Han & 1 & & 1 & \\
\hline Minority & $0.668(0.340-1.311)$ & 0.296 & $0.884(0.540-1.448)$ & \\
\hline Histological type & & & & 0.553 \\
\hline DNKC & 1 & & 1 & \\
\hline UCNT & $0.764(0.395-1.475)$ & 0.508 & $0.850(0.535-1.350)$ & \\
\hline Tumor size & & & & 0.484 \\
\hline $\mathrm{T} 1-3$ & 1 & & 1 & \\
\hline $\mathrm{T} 4$ & $1.283(0.673-2.444)$ & 0.516 & $1.198(0.760-1.888)$ & \\
\hline Lymph node status & & & & 0.016 \\
\hline N0-2 & 1 & & 1 & \\
\hline N3 & $0.347(0.145-0.829)$ & 0.024 & $0.402(0.193-0.835)$ & \\
\hline Distant metastasis & & & & 0.997 \\
\hline M0 & 1 & & 1 & \\
\hline M1 & $0.832(0.180-3.840)$ & 0.873 & $1.002(0.328-3.059)$ & \\
\hline Stage grouping & & & & 0.543 \\
\hline I-III & 1 & & 1 & \\
\hline IV & $0.665(0.289-1.529)$ & 0.385 & $0.809(0.438-1.495)$ & \\
\hline
\end{tabular}

expression or tumorigenesis. Zhang et al (18) demonstrated that the promoter variant rs2071559 $\mathrm{T}$ was associated with reduced susceptibility to atherothrombotic stroke; however, it was inversely associated with the development of coronary 
artery lesion in Kawasaki disease patients (19), implying that the $\mathrm{T}$ allele could increase neovascularization. In addition, as suggested by the data of Kariž and Petrovič (20), the rs2071559 $\mathrm{CC}$ genotype is a risk factor for myocardial infarction in Caucasians with type 2 diabetes mellitus.

Tumor growth and metastasis is dependent on the neovascularization of its surroundings. Depletion of the tumor blood supply inhibits growth and metastasis (21). Studies have demonstrated that the VEGFR2 signaling pathway performs an important role in tumor neovascularization and could serve as a promising target for anti-tumor therapy. Duff et al (22) showed that VEGFC and VEGFR2 were co-expressed and correlated with a number of metastatic lymph nodes. Another study has also shown that VEGFA could induce tumor neovascularization and lymph node lymphangiogenesis, and even promote lymphatic metastasis, through the VEGFR2 pathway (23). Together, these findings shed light on the findings of the present study. VEGFR2 in patients with NPC with the rs2071559 $\mathrm{T}$ allele may exhibit higher transcriptional activity, subsequently increasing the migratory ability of NPC cells, in concert with certain other factors. The present study also found that patients with NPC with the rs2071559 C allele had decreased lymphatic metastasis, but no difference in NPC tumorigenesis. Additional studies are required to develop a detailed mechanism explaining these observations.

There are also numerous studies that have found that VEGFR2 affects the tumor response to radio-chemotherapy and other treatments. Nagy et al (24) found by multivariate analysis that only the expression of VEGFR2, and not patient age or tumor size, predicts the response of cervical carcinoma to radio-chemotherapy. Rydén et al (25) also found that tumor-specific expression of VEGFR2 was associated with an impaired response to the adjuvant tamoxifen in breast cancer. However, certain studies have implied that a decrease in the expression of VEGFR2 could increase the response of breast cancer to chemotherapy. Mele et al (26) found that VEGFR2 expression in patients with breast cancer increased with treatment with either tamoxifen or epirubicin alone, but decreased in patients receiving tamoxifen plus epirubicin. Sorafenib, the first FDA-approved targeted agent for the treatment of advanced renal cell carcinoma (RCC) and hepatocellular carcinoma (HCC), was initially identified as a Raf kinase inhibitor (27); however, it also inhibits VEGFR2. Therefore, Escudier et al (28) found that rs2071559 can predict sorafenib efficacy in patients with metastatic RCC, and Zheng et al (29) demonstrated that rs2071559 was an independent factor in overall survival rate of patients with advanced HCC. These observations imply the potential synergism of such drugs. The risk of serious hematologic complications, including neutropenia, should be considered if anti-VEGF drugs are to be administered with chemotherapy (30). Assessing the maturation state of the microvessels, however, may allow improved characterization of the vasculature and could prove useful in guiding anti-angiogenic treatment $(31,32)$.

There are potential limitations of the present study. The VEGFR2 gene is a polymorphic gene, and only rs2071559 was investigated. Other SNPs within VEGFR2 gene may contribute to gene regulation $(1,7,33)$. Thus, additional studies on other functional SNPs and haplotypes are required to delineate the genetic contribution of VEGFR2 polymorphisms to NPC. Second, the sample size was relatively small. Additional studies with larger populations are required to define the role of rs2071559 polymorphisms in the onset and course of NPC.

To conclude, the present results suggest that the rs2071559 polymorphism is associated with lymphatic metastasis of NPC, and may be a good prognostic indicator in patients with NPC. However, the precise molecular mechanism should been elucidated in further studies.

\section{Acknowledgements}

The present study was supported by the National Natural Science Foundation of China (grant no. 30960103).

\section{References}

1. Wee JT, Ha TC, Loong SL and Qian CN: Is nasopharyngeal cancer really a 'Cantonese cancer'? Chin J Cancer 29: 517-526, 2010.

2. Guo XC, Scott K, Liu Y, Dean M, David V, Nelson GW, Johnson RC, Dilks HH, Lautenberger J, Kessing B, et al: Genetic factors leading to chronic Epstein-Barr virus infection and nasopharyngeal carcinoma in South East China: Study design, methods and feasibility. Hum Genomics 2: 365-375, 2006.

3. Försti A, Jin Q, Altieri A, Johansson R, Wagner K, Enquist K, Grzybowska E, Pamula J, Pekala W, Hallmans G, et al: Polymorphisms in the KDR and POSTN genes: Association with breast cancer susceptibility and prognosis. Breast Cancer Res Treat 101: 83-93, 2007.

4. Folkman J: Tumor angiogenesis: Therapeutic implications. N Engl J Med 285: 1182-1186, 1971.

5. Carmeliet P and Jain RK: Angiogenesis in cancer and other diseases. Nature 407: 249-257, 2000

6. Guo P, Xu L, Pan S, Brekken RA, Yang ST, Whitaker GB, Nagane M, Thorpe PE, Rosenbaum JS, Su Huang HJ, et al: Vascular endothelial growth factor isoforms display distinct activities in promoting tumor angiogenesis at different anatomic sites. Cancer Res 61: 8569-8577, 2001.

7. Brenner RM, Nayak NR, Slayden OD, Critchley HO and Kelly RW: Premenstrual and menstrual changes in the macaque and human endometrium: Relevance to endometriosis. Ann N Y Acad Sci 955: 60-74, 86-88, 396-406, 2002.

8. Qi L, Robinson WA, Brady BM and Glode LM: Migration and invasion of human prostate cancer cells is related to expression of VEGF and its receptors. Anticancer Res 23: 3917-3922, 2003.

9. Waltenberger J, Claesson-Welsh L, Siegbahn A, Shibuya M and Heldin CH: Different signal transduction properties of KDR and Flt1, two receptors for vascular endothelial growth factor. J Biol Chem 269: 26988-26995, 1994.

10. Iughetti P, Suzuki O, Godoi PH, Alves VA, Sertié AL, Zorick T, Soares F, Camargo A, Moreira ES, di Loreto C et al: A polymorphism in endostatin, an angiogenesis inhibitor, predisposes for the development of prostatic adenocarcinoma. Cancer Res 61: 7375-7378, 2001.

11. Howell WM, Bateman AC, Turner SJ, Collins A and Theaker JM: Influence of vascular endothelial growth factor single nucleotide polymorphisms on tumour development in cutaneous malignant melanoma. Genes Immun 3: 229-232, 2002.

12. Balasubramanian SP, Brown NJ and Reed MW: Role of genetic polymorphisms in tumour angiogenesis. Br J Cancer 87: 1057-1065, 2002

13. Wang Y, Zheng Y, Zhang W, Yu H, Lou K, Zhang Y, Qin Q, Zhao B, Yang Y and Hui R: Polymorphisms of KDR Gene are associated with coronary heart disease. J Am Coll Cardiol 50: 760-767, 2007.

14. Thompson L: World Health Organization classification of tumours: Pathology and genetics of head and neck tumours. Ear Nose Throat J 85: 74, 2006.

15. Sobin LH, Gospodarowicz MK and Wittekind C: TNM Classification of Malignant Tumors. 7th edition. Wiley-Blackwell, Oxford, 2009.

16. Patterson C, Perrella MA, Hsieh CM, Yoshizumi M, Lee ME and Haber E: Cloning and functional analysis of the promoter for KDR/flk-1, a receptor for vascular endothelial growth factor. J Biol Chem 270: 23111-23118,1995. 
17. An SJ, Chen ZH, Lin QX, Su J, Chen HJ, Lin JY and Wu YL: The $-271 \mathrm{G}>$ A polymorphism of kinase insert domain-containing receptor gene regulates its transcription level in patients with non-small cell lung cancer. BMC Cancer 9: 144, 2009.

18. Zhang W, Sun K, Zhen Y, Wang D, Wang Y, Chen J, Xu J, Hu FB and Hui R: VEGF receptor-2 variants are associated with susceptibility to stroke and recurrence. Stroke 40: 2720-2726, 2009.

19. Kariyazono H, Ohno T, Khajoee V, Ihara K, Kusuhara K, Kinukawa N, Mizuno Y and Hara T: Association of vascular endothelial growth factor (VEGF) and VEGF receptor gene polymorphisms with coronary artery lesions of Kawasaki Disease. Pediatr Res 56: 953-959, 2004.

20. Kariž S and Petrovič D: Minor association of kinase insert domain-containing receptor gene polymorphism (rs2071559) with myocardial infarction in Caucasians with type 2 diabetes mellitus: Case-control cross-sectional study. Clin Biochem 47: 192-196, 2014.

21. Shalaby F, Rossant J, Yamaguchi TP, Gertsenstein M, Wu XF, Breitman ML and Schuh AC: Failure of blood-island formation and vasculogenesis in Flk-1 deficient mice. Nature 376: 62-66, 1995.

22. Duff SE, Jeziorska M, Rosa DD, Kumar S, Haboubi N, Sherlock D, O'Dwyer ST and Jayson GC: Vascular endothelial growth factors and receptors in colorectal cancer: Implications for anti-angiogenic therapy. Eur J Cancer 42: 112-117, 2006.

23. Hirakawa S, Kodama S, Kunstfeld R, Kajiya K, Brown LF and Detmar M: VEGF-A induces tumor and sentinel lymph node lymphangiogenesis and promotes lymphatic metastasis. J Exp Med 201: 1089-1099, 2005 .

24. Nagy VM, Buiga R, Brie I, Todor N, Tudoran O, Ordeanu C, Virág P, Tarta O, Rus M and Bălăcescu O: Expression of VEGF, VEGFR, EGFR, COX-2 and MVD in cervical carcinoma, in relation with the response to radio-chemotherapy. Rom J Morphol Embryol 52: 53-59, 2011.

25. Rydén L, Jirström K, Haglund M, Stål O and Fernö M: Epidermal growth factor receptor and vascular endothelial growth factor receptor 2 are specific biomarkers in triple-negative breast cancer. Results from a controlled randomized trial with long-term follow-up. Breast Cancer Res Treat 120: 491-498, 2010.

26. Mele T, Generali D, Fox S, Brizzi MP, Bersiga A, Milani M, Allevi G, Bonardi S, Aguggini S, Volante M, et al: Anti-angiogenic effect of tamoxifen combined with epirubicin in breast cancer patients. Breast Cancer Res Treat 123: 795-804, 2010.
27. Wilhelm SM, Carter C, Tang L, Wilkie D, McNabola A, Rong H, Chen C, Zhang X, Vincent P, McHugh M, et al: BAY 43-9006 exhibits broad spectrum oral antitumor activity and targets the RAF/MEK/ERK pathway and receptor tyrosine kinases involved in tumor progression and angiogenesis. Cancer Res 64: 7099-7109, 2004

28. Escudier B, Rini BI, Motzer RJ, Tarazi J, Kim S, Huang X, Rosbrook B, English PA, Loomis AK and Williams JA: Genotype correlations with blood pressure and efficacy from a randomized phase iii trial of second-line axitinib versus sorafenib in metastatic renal cell carcinoma. Clin Genitourin Cancer 13: 328-337, 2015.

29. Zheng YB, Zhan MX, Zhao W, Liu B, Huang JW, He X, Fu SR, Zhao Y, Li Y, Hu BS and Lu LG: The relationship of kinase insert domain receptor gene polymorphisms and clinical outcome in advanced hepatocellular carcinoma patients treated with sorafenib. Med Oncol 31: 209, 2014.

30. Novitskiy SV, Csiki I, Huang Y, Johnson DH, Harth EM, Carbone DP and Dikov MM: Anti-vascular endothelial growth factor treatment in combination with chemotherapy delays hematopoietic recovery due to decreased proliferation of bone marrow hematopoietic progenitor cells. J Thorac Oncol 5: 1410-1415, 2010.

31. Hlatky L, Hahnfeldt $\mathrm{P}$ and Folkman J: Clinical application of antiangiogenic therapy: Microvessel density, what it does and doesn't tell us. J Natl Cancer Inst 94: 883-893, 2002.

32. Vermeulen PB, Gasparini G, Fox SB, Colpaert C, Marson LP, Gion M, Beliën JA, de Waal RM, Van Marck E, Magnani E, et al: Second international consensus on the methodology and criteria of evaluation of angiogenesis quantification in solid human tumours. Eur J Cancer 38: 1564-1579, 2002.

33. Park HW, Shin ES, Lee JE, Kwon HS, Chun E, Kim SS, Chang YS, Kim YK, Min KU, Kim YY and Cho SH: Multilocus analysis of atopy in Korean children using multifactor-dimensionality reduction. Thorax 62: 265-269, 2007. 